\title{
The Nursing Care in Front of the Dying Process in Oncology
}

Gunnar Glauco De Cunto Taets*

Universidade Federal do Rio de Janeiro, Brazil

*Corresponding author: De Cunto Taets GG, Universidade Federal do Rio de Janeiro Fundamentos de Enfermagem, Estrada da Boiuna, 1133 casa 57, Taquara, Rio de Janeiro, RJ 22723-021, Brazil, Tel: +5521980375799; E-mail: oenfermeiro2007@hotmail.com

Received date: Feb 17, 2016; Accepted date: Mar 29, 2016; Published date: Apr 06, 2016

Copyright: $@ 2016$ De Cunto Taets GG. This is an open-access article distributed under the terms of the Creative Commons Attribution License, which permits unrestricted use, distribution, and reproduction in any medium, provided the original author and source are credited.

\begin{abstract}
Introduction: This study deals with the theme of the process of death/dying experienced by cancer patients from the perspective of nursing theoretically based the Elizabeth Kübler-Ross studies pioneered in describing the attitudes and emotional reactions raised by harmonizing death in terminally ill patients.
\end{abstract}

Objective: To describe the care in nursing about the process of death/dying patient in oncology. Methods: integrative review with qualitative approach.

Results: It was observed that the nursing care in oncology front of the patient in the process of death/dying is a daily challenge in dealing with the worsening condition of the patient, acceptance, fear, anxiety and confidence, taking care of the patient with no chance of cure, but not out of the possibility of care.

Conclusion: This study showed a body of knowledge about the process of death/dying experienced by patients hospitalized in Oncology Units from the perspective of nurses tending to a technical assistance, fragmented and impregnated by rules and routines at the expense of the essence of human care, in favour of a process of death and dying with dignity.

Keywords: Nursing care; Death; Oncology; Qualitative research; Intensive care units

\section{Introduction}

The nursing professional is one who spends more time near the patient hospitalized in an ICU and to deal with hospital mortality situation in the daily care, occurrence in which he gives the materialization of the process of dying and death, and is, certainly an experience steeped in scientific meanings, but also social significance, cultural and mostly subjective [1].

Death is a controversial issue which raises the nursing professional feelings and different attitudes. Although it is part of the natural cycle of life, death is still today a controversial issue, sometimes avoided and many do not understand, generating even fear and anxiety.

Die, scientifically is ceasing to exist; when the body affected by a disease or accident of some kind is the failure of vital organs, having a progressive stop all activity in the body and may be a sudden form (acute illnesses, accidents) or slow (chronic diseases), then a degeneration of tissues [2].

Death is not only a biological fact but a process socially constructed, that is not differentiated from other dimensions of the universe of social relations. Thus, death is present in our daily lives and, regardless of their causes or forms, their big stage remains hospitals and health institutions.

Addressing the topic of death/dying from the perspective of the science of human care, nursing is a challenge, having seen the taboo that this word carries death. Especially in health care, where all actions are focused on the living, death carries with it the stigma of failure, impotence, where the acts performed for maintenance of life have not been effective.

The nursing team faces almost every day and death, regardless of professional and life experience, almost all the face with a certain sense of uncertainty, despair and distress. Uncertainty because they know it is providing all possible care for the patient's well-being, prolong life and prevent her death; despair because you feel powerless to do anything that will save alive; trouble because you do not know how to effectively communicate with patients and their families. All these factors severely burden the nurse who seeks care for those whose death is often an unavoidable situation.

Being the inevitable and frequent death in the ICU, not all nurses understand it, welcome it and react to it the same way. This is no doubt a good argument to consider the study of this very important topic.

Research problem: How the nursing take care of cancer patients facing the process of death/dying?

Objective: describe the nursing care in front of the process of dying in Oncology Units.

\section{Methods}

This is an integrative review study with qualitative approach. It was conducted a search in the online database of the Virtual Health Library (VHL) crossing the descriptors: Death, nursing care, intensive care units. The first search yielded 233 articles. These separate those with the online available full text and find 44 articles. Of these 44 , it selected only those directly related to the purpose of the study reaching the total of 16 articles that formed then the sample. 
First the material to be analyzed was organized in order to make it operational, systematizing iniciais. Procedemos ideas to a short reading, estabelendo the contacts with the collected data. It explored the material for the definition of the categories. The exploitation of the material was an important step because it allowed the interpretation and inference about the data collected.

\section{Findings}

The results presented below, were grouped into three categories: The process of dying and its phases; the emotional aspect of nursing professionals facing death; communication in nursing and the process of death/dying.

\section{The process of dying and its phases}

This study provides the theoretical reference the Kübler-Ross studies pioneered in describing the attitudes and emotional responses raised by the approach of death in terminally ill patients. His works describe the identification of five stages that a patient can experience during his terminal illness, which are: denial, anger, bargaining, depression and acceptance [3].

Denial can be a temporary defense or in some cases can hold up to the end. The patient distrusts exchange tests or competence of the health care team. Generally thought that translates this defense is, "No, I do not, it's true."

Anger is the phase in which they arise feelings of anger, anger, and resentment, "why me?". It becomes more difficult to deal with the patient, as anger spreads in all directions, projecting into the environment, often without "plausible reason".

In the bargain the patient makes promises for a prolongation of life or a few days without pain or physical ailments. The bargains are made with God, for the most part and, psychologically, may be associated with a secluded fault.

Depression can show their aloofness or stoicism, with a sense of great loss. The difficulties of long-term treatment and hospitalization increase the sadness that, together with other feelings, cause depression.

Acceptance is one in which the patient comes to accept your situation and your destination. It is the period in which the family may need help, understanding and support, as the patient is a certain peace and the circle of interest decreases. However, there are patients who keep the conflict with death without achieving this stage.

There is an order to the occurrence of these events, nor a chronology, and the patient may experience more than one of these phases simultaneously for the same period or even not experience some of them.

These phases are as defense mechanisms to face the unknown process of dying, in which conflicts emotional, material, psychological, familial, social, spiritual, among others, appear sharply, directly affecting the relationship with the health team [4].

However, even if the death is a very present phenomenon in everyday life of nursing professionals, there is a certain difficulty they have to not only accept, but in the proper handling of the situation, especially when it involves family [5,6]. Therefore, although it is essential to the individual care perspective, not just the biological body, rescue the human in the process of death and dying is presented not as easy [7].

\section{The emotional aspect of nursing professionals facing death}

Nursing care covers the entire life cycle of the human being, that is, from birth to the afterlife. Thus, it is worth considering the role of the nursing staff does not end with the confirmation of death. In addition to the body of the preparation procedures, the family of the patient requires care and attention to experience the moments of death more evenly process.

Living with death daily, despite the availability of resources and the unremitting struggle of professionals to sustain life and promote the rehabilitation of patients. Caring involves human acts in the process of assisting the individual, family or community, so that involves equitably interpersonal relationships based on humanistic values and scientific knowledge.

There are situations in which, despite all the health team effort results in death of the patient, and this happens to be experienced as intense frustration by professionals who feel they were not able to save the lives entrusted to them [8].

This is by proximity to constant situations that reveal the human possibility of death, conditions under which these professionals find themselves before the expectation that its function is to heal and restore health to all who seek them, keeping in mind that death is inherent the human condition [8].

This way of thinking stems from vocational training, in which the nurse feels committed to life, and it is for the preservation of which should feel empowered, forgetting, however, that death is part of life; academic training grounded in healing, and it is his greatest gratification. So when in their daily work requires dealing with death in general feels unprepared, and tends to move away from it.

\section{Communication in nursing and the process of death/dying}

Nursing is to establish closer communication from the care relationship and, consequently, better understand the patient as a person, because it is more present during the terminal stage [9].

Requests from patients with end-stage sometimes are difficult to understand, so nurses must have the knowledge and communication skills to decode essential information, reducing the distress of the dying and providing quality care [10].

In this context, communication skills to deal with the dying process is a necessary tool that enable the professional to identify which of the five stages of the dying process, as indicated by the works of KublerRoss, the patient is, and thus assist qualitative and comprehensive way in its assistance.

It is consistent to understand that the issues surrounding the death, in particular the issues of subjective order, always figured among the greatest difficulties experienced by health professionals, especially nurses when they need to provide care to the patient in the process of death [11].

\section{Discussion}

The impotence of not being able to conquer death is a constant in the reports, referring the subject, sometimes the phenomenon of his own death. These feelings are more intense when the professionals get 
on that account, despite the technology, remain limited to eliminate death.

Death causes anguish, horror and pain. "The pain caused by death only if there is the individuality of the dead is present and recognized: the more the dead is close, the more violent is the pain"[12]. It adds that the loss of the patient felt more intensely when emotional ties are established between the patient and the nurse. These professionals are frustrated and find it difficult to accept and cope with the death of the patient.

Doubt, confusion and uncertainty are the feelings involved with the care process. $\mathrm{Na}$ author points out that there is only fight if there was link. The higher the bond established with the patient, the greater the suffering of the professional when he passes away [13]. It is noticed in the data collected that, without creating bond with the patient, suffering is reduced when it passes away.

The emotional aspect of health professionals it is important because these also create defense mechanisms that help in coping with the death and dying process. To be prepared for the maintenance of life, death and dying, in their daily lives, raise feelings of frustration, sadness, loss, impotence, stress and guilt. In general, the lack of preparation leads the professional to move away from the situation [14].

The confrontation with death is an arduous task for nurses working in the ICU. We can not imagine as a gesture, a word, a pat can be heaven, paradise for someone who goes through this process.

It is noticed that in everyday practice nursing work tends to a technical assistance, fragmented and impregnated by rules and routines at the expense of the essence of human care, towards a process of death and dying with dignity. Authors complements the ICUs are now the terrible symbol of the sad death, lonelier and more dehumanized [3].

Care for the patient in the process of death / dying should be considered as rewarding as the resuscitation of a patient who had a cardiac arrest, considering death as part of life. Provide a good death is to provide nursing care with dignity and respect, terminally with minimal suffering and pain.

The certainty of finitude not seem to find space in the technological apparatus that is the world of a UTI. The technical / scientific knowledge in such a way has evolved and become more sophisticated that professionals are trained to avoid death, as if this was not part of life. As a result, there is a lack of trained professionals for the farewell.

In the analyzed studies revealed a large emphasis on technicality and very little present, if not we say absent, care emotional and spiritual level in relation to the patient in the process of death / dying.

Handle a corpse, dry, clean their secretions with cotton plug their holes before intact, it seems to be pleasing to the eye and the senses. It is the loss of a patient, is the negation of life, profession of care, is the confrontation with death and lost challenge. It is encountering impotence before the inevitability of death, which is not found in books, or in classes or in discussions about death and dying. In its broadest dimension, it is present in practice, in which only the techniques can reduce this to a procedure like many others.

The statements of nursing professionals interviewed in the studies analyzed emphasize the technical care, very present situation in intensive care units. In the space where the nursing professional work, paying huge attention to develop techniques to prolong life, as in the case of a UTI, other feelings emerge, permeating the atmosphere of your labor, affective and emotional struggle related to a confusing impotence that the lines identified as failure, frustration, weakness and disability.

The nursing care in intensive care is a challenging care [15], a daily challenge in dealing with the worsening condition of the patient, acceptance, fear, anxiety and confidence, taking care of the patient with no chance of cure but not out of the possibility of care.

\section{Conclusions}

Considering death part of life, it is necessary to conduct further research to contribute to this area of knowledge, with regard to the conditions of the specialized areas of professionals who deal daily with the finitude, as in the ICU setting. Expand knowledge about death does not allow the individual to understand in all its complexity, but allow for a more positive attitude towards it, providing act "professional" more ethical, more philosophical, more human. There is a need to understand that death is not a challenge to life, but an integral part of it.

According with an author: "Like everything that is human, life is also fatigue that longs for sleep" [16].

\section{References}

1. Domingues DA Nascimento Silva AB, Silva MC, Pereira MHM (2006) Significance of hospital death for nurses and doctors. Magazine Rene Fortaleza 7: 52-60.

2. Moreira A, Lisbon M (2006) Death between the public and the private: Reflections for the practice of nursing. UERJ Nursing Journal, 14, 447-454.

3. Kubler-Ross E (1998) About death and dying: that the terminally ill have to teach doctors, nurses, religious and their own relatives. 8th ed. São Paulo: Martins Fontes.

4. Paduan MA (1984) The education of Nursing undergraduate students regarding death and dying [Thesis]. Sao Paulo (PR) Ribeirao Preto College of Nursing, 1984.

5. Poles K, Bousso RS (2006) [Sharing the death process with the family: a nurse's experience in the pediatric ICU]. Rev Lat Am Nursing 14: 207-213.

6. Rodrigues MVC, Ferreira ED, Menezes TMO (2010) Nurse Communication with cancer patients with no chance of cure. Rev Enferm UERJ 18: 86-91.

7. Costa JC Lopes K, Rebolledo DMC, Oak LNR, Lemos JF, et al. (2008) The nurse in the patient out of terapêuticancológicas possibilities: a literature review. Vita et Sanitas 2: 150-61.

8. Boemer MR (1998) Death and dying. (3rdedtn). Ribeirao Preto: Holos.

9. Esslinger I (2004) The patient, staff and care: who is life anyway? In: Humanization and palliative care. Sao Paulo: Loyola 10: 149-62.

10. Silva ALL, Ruiz IN (2003) Taking care, death and dying: significations for Nursing professionals. Estud Psicol 20: 15-25.

11. Kovacs MJ (2003) Education for Death: challenge in training health and education professionals. Sao Paulo, House Psicologo.

12. Morin E (1997) Man and death. Translation Cleone Augusto Rodrigues. Rio de Janeiro: Imago.

13. Horta AL (2002) The process of death and dying in the patient, family and the nursing staff. Nursing (São Paulo) 15-7.

14. Baraldi S, Silva MJP (2000) Reflections on the influence of social structure on death - dying process. Nursing 24: 14-17.

15. Rabbit MJ (2006) [Caring gestures in nursing]. Rev Bras Enferm 59: 745-751. 
Citation: De Cunto Taets GG (2016) The Nursing Care in Front of the Dying Process in Oncology. J Nurs Care 5: 337. doi: 10.4172/2167-1168.1000337

Page 4 of 4

16. Alves R (1996) Time to die. In: Alves R (ed.) Return and tender: chronic. (7thedtn) Campinas: Papirus. 